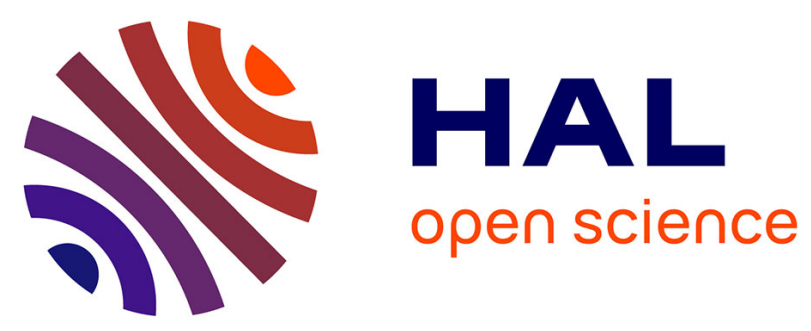

\title{
Evolution of silent myocardial ischaemia prevalence and cardiovascular disease risk factor management in Type 2 diabetes over a 10-year period: an observational study
} A. Sultan, F. Perriard, V. Macioce, Denis Mariano-Goulart, C. Boegner, J.-P. Daures, Antoine Avignon

\section{To cite this version:}

A. Sultan, F. Perriard, V. Macioce, Denis Mariano-Goulart, C. Boegner, et al.. Evolution of silent myocardial ischaemia prevalence and cardiovascular disease risk factor management in Type 2 diabetes over a 10-year period: an observational study. Diabetic Medicine, 2017, 34 (9), pp.1244-1251. 10.1111/dme.13364 . hal-01762635

\section{HAL Id: hal-01762635 \\ https://hal.science/hal-01762635}

Submitted on 19 Dec 2019

HAL is a multi-disciplinary open access archive for the deposit and dissemination of scientific research documents, whether they are published or not. The documents may come from teaching and research institutions in France or abroad, or from public or private research centers.
L'archive ouverte pluridisciplinaire HAL, est destinée au dépôt et à la diffusion de documents scientifiques de niveau recherche, publiés ou non, émanant des établissements d'enseignement et de recherche français ou étrangers, des laboratoires publics ou privés. 


\title{
Evolution of silent myocardial ischaemia prevalence and cardiovascular disease risk factor management in Type 2 diabetes over a 10-year period: an observational study
}

\author{
A. Sultan ${ }^{1,2,3}$ D , F. Perriard ${ }^{4}$, V. Macioce ${ }^{5}$, D. Mariano-Goulart ${ }^{6}$, C. Boegner ${ }^{1}$, J.-P. Daures ${ }^{4}$ \\ and A. Avignon $1,2,3$
}

'Department of Endocrinology, Diabetology and Nutrition, CHRU, Montpellier, ${ }^{2}$ UMR CNRS 9214, Inserm U1046, ${ }^{3}$ University of Montpellier, ${ }^{4}$ Laboratory of Biostatistics, University Institute of Clinical Research, ${ }^{5}$ Clinical Research and Epidemiology Unit, University Hospital and ${ }^{6}$ Departement de Médecine Nucléaire, CHU Lapeyronie, Université Montpellier, Montpellier, France

\section{Abstract}

Aims To assess the evolution of silent myocardial ischaemia prevalence and of cardiovascular disease risk factor management over 10 years in people with Type 2 diabetes.

Methods This repeated cross-sectional study prospectively included 770 people with Type 2 diabetes who presented at our centre in the period 1999-2009. All had at least one additional cardiovascular disease risk factor, no history of coronary disease and were screened for silent myocardial ischaemia using myocardial perfusion imaging. The prevalence of silent myocardial ischaemia, clinical and biological variables and treatments were collected and compared among participants screened in three periods: 1999 to 2002; 2003 to 2005; and 2006 to 2009. We also identified predictive factors for silent myocardial ischaemia.

Results Participants had a mean \pm SD age of $62.3 \pm 9.3$ years, $57.4 \%$ were men and the mean time from diagnosis of diabetes was $13.4 \pm 9.3$ years. Overall, silent myocardial ischaemia screening was positive in $13.9 \%$ of participants. This prevalence decreased sharply over the 10-year study period $(22.6 \%$ in $1999-2002,13.7 \%$ in $2003-2005$ and $5.9 \%$ in 2006-2009; $P<0.0001$ ). In parallel, diastolic and systolic blood pressure, $\mathrm{HbA}_{1 \mathrm{c}}$ and LDL cholesterol significantly decreased and glitazone and statin use increased (all $P<0.001$ ). Male gender, peripheral artery disease, diastolic blood pressure $>80 \mathrm{mmHg}$ and LDL cholesterol $>2.6 \mathrm{mmol} / \mathrm{l}$ were independently associated with silent myocardial ischaemia. Further adjustment showed the screening period had a significant effect, which erased the effects of diastolic blood pressure and LDL cholesterol.

Conclusions The prevalence of silent myocardial ischaemia decreased sharply over time, and control of the main cardiovascular disease risk factors improved. Although the causality link cannot be established, the present study supports current recommendations advocating glycaemic control and intensive management of cardiovascular factors instead of systematic screening.

\section{Introduction}

In 2013, 382 million people had diabetes worldwide, and this number is expected to reach 592 million by 2035 [1]. The association between diabetes and cardiovascular disease is well established; coronary artery disease is the leading cause of death in diabetes [2]. Importantly, coronary artery disease is also more often silent in people with diabetes [3].

Correspondence to: Ariane Sultan. E-mail: a-sultan@chu-montpellier.fr
Given the elevated risk of cardiovascular events and the higher prevalence of silent myocardial ischaemia in diabetes, screening asymptomatic people with diabetes for silent myocardial ischaemia was an appealing concept; however, many factors argue against implementing a broad-based screening programme [4-6]. Despite an important number of trials, the usefulness of silent myocardial ischaemia screening in people with Type 2 diabetes remains controversial, especially in the context of intensive therapy with regard to risk factors. Very few data have shown that a prospectively applied screening programme improves outcomes in 


\section{What's new?}

- The prevalence of silent myocardial ischaemia decreased sharply over 10 years (from $22.6 \%$ in 1999-2002 to $5.9 \%$ in 2006-2009).

- In parallel, the management of cardiovascular disease risk factors (diastolic and systolic blood pressure, $\mathrm{HbA}_{1 \mathrm{c}}$, LDL cholesterol) improved, and glitazone and statin use increased.

- Intensive management of cardiovascular factors could be recommended instead of systematic screening for silent myocardial ischaemia in people with Type 2 diabetes at high risk.

asymptomatic people with diabetes. Indeed, the Detection of Ischaemia in Asymptomatic Diabetics (DIAD) study is a randomized multicentre trial of silent myocardial ischaemia screening in asymptomatic adults with diabetes mellitus. A total of 522 people were allocated to systematic silent myocardial ischaemia screening, while 562 people were assigned to regular follow-up. At 5 years, the overall cardiac event rate was not significantly different between the groups, arguing against systematic silent myocardial ischaemia screening [6]. More recently, the Factor-64 randomized clinical trial was carried out in people with asymptomatic Type 1 or Type 2 diabetes [7]. It also reported that systematic coronary artery disease screening did not reduce the composite rate of all-cause mortality, non-fatal myocardial infarction, or unstable angina requiring hospitalization. The DYNAMIT randomized trial attempted to assess the effect of silent myocardial ischaemia screening on cardiovascular events [8], although it was stopped prematurely after 631 inclusions because of recruitment difficulties. A metaanalysis of DYNAMIT and DIAD studies showed no significant benefit of systematic screening [8]. Further, a commonly admitted rationale for systematic research of silent myocardial ischaemia in asymptomatic patients in general is to intensify treatment of risk factors. This might not apply to treatment of risk factors in people with diabetes. Indeed, since 2001, the National Cholesterol Education Program recommended more aggressive treatment for high lipid levels and hypertension simply on the basis of diabetes status [5]. More recently, the American Diabetes Association did not recommend routine screening for silent myocardial ischaemia in asymptomatic people as it does not improve outcomes as long as cardiovascular disease risk factors are treated [4]. Similarly, European guidelines recommend the screening of only patients at particularly high risk, such as those with evidence of peripheral artery disease, high coronary artery calcium scores or proteinuria [9].

We have routinely screened for silent myocardial ischaemia in all patients with high-risk Type 2 diabetes referred to our institution since 1999, according to French guidelines
[10]. In the context of the controversy over the usefulness of this screening, to the aim of the present study was to evaluate the evolution of the prevalence of silent myocardial ischaemia and the evolution of cardiovascular disease risk factor management in the period from 1999 to 2009.

\section{Materials and methods}

We carried out a repeated cross-sectional study from a previously described cohort [11] of participants with Type 2 diabetes, screened for silent myocardial ischaemia. All asymptomatic people with Type 2 diabetes referred to our diabetes clinic (either new referrals or those returning for routine follow-up) at an academic university hospital in Montpellier, France between 1999 and December 2009 were prospectively assessed for eligibility. People admitted thereafter were not included because at that point our team considered that systematic screening was no longer useful, and since January 2010, screening has only been performed in specific patients at our centre. Diabetes was diagnosed according to American Diabetes Association criteria available at that time (Expert Committee on the Diagnosis and Classification of Diabetes Mellitus, 1997). Participants were considered to have Type 2 diabetes if they had no history of ketosis and if they did not initiate insulin treatment either in the 2 years after the diagnosis or before the age of 40 years.

At inclusion, participants were considered for silent myocardial ischaemia screening according to the Frenchspeaking diabetes association (formerly ALFEDIAM) guidelines currently available at that time [10]. Included participants, therefore, had at least one of the following cardiovascular disease risk factors: age $\geq 60$ years; active smoking habit; albuminuria; hypertension (systolic blood pressure $\geq 130 \mathrm{mmHg}$ or diastolic blood pressure $\geq 80$ $\mathrm{mmHg}$ ); dyslipidaemia (LDL cholesterol $\geq 3.4 \mathrm{mmol} / \mathrm{l}$ and/ or HDL cholesterol $<1.0 \mathrm{mmol} / \mathrm{l}$ or triglycerides $\geq 1.7 \mathrm{mmol} / \mathrm{l}$ or lipid-lowering therapy); family history of premature coronary artery disease (i.e. occurring before age 55 years in a male first-degree relative or before age 65 years in a female first-degree relative); and peripheral artery disease (considered when one or more peripheral arterial pulse was absent at clinical examination and/or when intermittent claudication and/or a history of revascularization of the lower limbs was present). Atherogenic dyslipidaemia was defined as triglycerides $\geq 2.26 \mathrm{mmol} / \mathrm{l}$ and HDL cholesterol $\leq 0.88 \mathrm{mmol} / \mathrm{l}$ [12]. Retinopathy was assessed by ophthalmoscopy. People with albumin excretion rate $>30 \mathrm{mg} /$ day and/or macroproteinuria and/or renal failure were considered to have diabetic nephropathy.

Exclusion criteria included: known ischaemic heart disease; electrocardiographic evidence of Q-wave myocardial infarction, ischaemic ST-segment or T-wave changes; critical illness or unstable haemodynamics; surgery within the previous 3 months; age $\geq 80$ years; contraindication to dipyridamole (such 
as history of severe bronchospasm); and previous silent myocardial ischaemia screening in the last 5 years.

Cardiovascular disease risk factors, family history of stroke or coronary disease, current medications and concomitant illnesses were recorded. Participants were considered to be active smokers if they currently smoked or had stopped smoking in the preceding 3 years. Blood pressure was measured with an automatic blood pressure monitor that was set to report the average of six blood pressure measurements, taken $5 \mathrm{~min}$ apart, after lying down for 15 min.

Each participant enrolled in the present study had given oral informed consent in accordance with the European directives as edited in 2001, which require no approval from an ethical committee for a study design as described herein.

\section{Treatments}

All participants had been receiving long-term treatment for atherosclerotic risk factors since 1999 according to recommendations available at that time, with stepwise implementation of behaviour modification and pharmacological therapy targeting hyperglycaemia, hypertension and dyslipidaemia. Medications were categorized as biguanide, sulfonylureas, $\alpha$-glucosidase inhibitors, glitazone, insulin, renin-angiotensin system blockers (either angiotensinconverting enzyme inhibitors or angiotensin II receptor antagonists), antiplatelet drugs and lipid-lowering drugs.

\section{Myocardial perfusion imaging}

Stress tests and myocardial perfusion imaging were performed as previously described [11]. Briefly, all participants underwent a combined dipyridamole $(0.75 \mathrm{mg} / \mathrm{kg})$ exercise stress test, followed by a same-day stress-rest imaging protocol using ${ }^{99 \mathrm{~m}} \mathrm{Tc}$-sestamibi $(1 \mathrm{mCi} / 10 \mathrm{~kg}$ body weight with a minimum of $7 \mathrm{mCi} ; 259 \mathrm{MBq})$. Stress and rest images were acquired, with the participant in prone position, $1 \mathrm{~h}$ after injection of ${ }^{99 \mathrm{~m}} \mathrm{Tc}$-sestamibi. Acquisition was performed using a double-headed gamma camera (GE-SMV DST-XL; GE Healthcare, Little Chalfont, UK) with lowenergy, high-resolution, parallel-hole collimators. Stress and rest acquisitions were ECG-gated (10\% R-R interval acceptance window, eight gated intervals). Silent myocardial ischaemia was defined as positive myocardial perfusion imaging (mean activity $<70 \%$ of the maximum myocardium activity in three of 20 segments). Two experienced nuclear medicine physicians, blinded to the clinical data, reviewed the scintigraphic images.

\section{Laboratory procedures}

Biological variables were evaluated in fasting conditions on the same day as silent myocardial ischaemia screening took place. Serum total cholesterol, HDL cholesterol and triglyceride levels were measured using routine enzymatic methods (Architect C8000; Abbott, Rungis France). LDL cholesterol was calculated using the Friedewald formula. $\mathrm{HbA}_{1 \mathrm{c}}$ was measured by a routine HPLC-based ion-exchange procedure (HA-8140; Menarini, Rungis, France). Enzymatic creatinine (Randox reagent, Mauguio, France) was measured and creatinine clearance was calculated using the Modification of Diet in Renal Disease equation. Urinary albumin excretion and proteinuria were measured via 24-h urine collections by immunoturbidimetry (Roche Cobasc502; Roche, Meylan, France). Microalbuminuria was defined as urinary albumin excretion values between 30 and $300 \mathrm{mg} /$ $24 \mathrm{~h}$. When urinary albumin excretion was $>300 \mathrm{mg} / 24 \mathrm{~h}$, proteinuria was measured and defined as values above $0.3 \mathrm{~g} /$ $24 \mathrm{~h}$.

\section{Statistical analysis}

A descriptive analysis was performed on all cardiovascular disease risk factors for people with and without silent myocardial ischaemia. Quantitative variables were described using mean values and standard deviations. As they were non-normally distributed, these variables were compared between people with and without silent myocardial ischaemia using the Mann-Whitney test. Qualitative variables were described using numbers and percentages and were compared using the Fisher's test. The level of statistical significance was set at 0.05 .

The cohort was then divided into groups based on the date of silent myocardial ischaemia screening. Group 1 included participants screened between July 1999 and December 2002, group 2 included those screened between January 2003 and December 2005 and group 3 included those screened between January 2006 and December 2009. Differences between these three periods of time were analysed using the chi-squared test for qualitative variables or the KruskalWallis test for quantitative variables. Missing data were not imputted. Multivariate analyses were implemented using unconditional logistic models. Variables were selected using a stepwise procedure, with an $\alpha$-to-enter value of 0.15 and $\alpha$ to-exit value of 0.05 . A first model was carried out using variables associated with silent myocardial ischaemia. In addition to those variables, screening period was introduced in a second model. Statistical analyses were performed using SAS version 9.1 (SAS Institute, Cary, NC, USA).

\section{Results}

\section{Patients' characteristics according to silent myocardial ischaemia status}

A total of 770 people with Type 2 diabetes were screened between 1999 and 2009, all of whom were included and analysed. Population characteristics at inclusion are presented in Table 1. Participants were aged $62.3 \pm 9.2$ years, 


\begin{tabular}{|c|c|c|c|c|c|}
\hline & $\begin{array}{l}\text { Missing } \\
\text { values }\end{array}$ & $\begin{array}{l}\text { Whole } \\
\text { cohort } \\
N=770\end{array}$ & $\begin{array}{l}\text { Patients with silent } \\
\text { myocardial ischaemia } \\
n=107\end{array}$ & $\begin{array}{l}\text { Patients without silent } \\
\text { myocardial ischaemia } \\
n=663\end{array}$ & $P$ \\
\hline Men, $n(\%)$ & 0 & $442(57.4)$ & $90(84.1)$ & $352(53.1)$ & $<0.0001$ \\
\hline Age, years & 0 & $62.3 \pm 9.3$ & $62.3 \pm 8.8$ & $62.3 \pm 9.3$ & 0.96 \\
\hline BMI, $\mathrm{kg} / \mathrm{m}^{2}$ & 13 & $30.3 \pm 5.7$ & $30.2 \pm 5.4$ & $30.4 \pm 5.8$ & 0.80 \\
\hline $\begin{array}{l}\text { Time from diagnosis of } \\
\text { diabetes, years }\end{array}$ & 12 & $13.4 \pm 9.3$ & $12.6 \pm 9.6$ & $13.5 \pm 9.2$ & 0.24 \\
\hline Smoking, $n(\%)$ & 0 & $183(23.8)$ & $27(25.2)$ & $153(23.5)$ & 0.71 \\
\hline Systolic blood pressure, $\mathrm{mmHg}$ & 1 & $132.0 \pm 18.1$ & $137.8 \pm 19.3$ & $131.0 \pm 17.7$ & 0.002 \\
\hline $\begin{array}{l}\text { Systolic blood pressure }>130 \\
\mathrm{mmHg}, n(\%)\end{array}$ & 1 & $445(57.9)$ & $70(65.4)$ & $375(56.7)$ & 0.09 \\
\hline $\begin{array}{l}\text { Diastolic blood pressure, } \\
\mathrm{mmHg}\end{array}$ & 1 & $72.8 \pm 10.7$ & $74.9 \pm 11.6$ & $72.4 \pm 10.5$ & 0.04 \\
\hline $\begin{array}{l}\text { Diastolic blood pressure }>80 \\
\mathrm{mmHg}, n(\%)\end{array}$ & 1 & $256(33.3)$ & $46(43.0)$ & $210(31.7)$ & 0.03 \\
\hline Hypertension, $n(\%)$ & 1 & $467(60.7)$ & $73(68.2)$ & $364(59.5)$ & 0.09 \\
\hline $\mathrm{HbA}_{1 \mathrm{c}}, \mathrm{mmol} / \mathrm{mol}$ & 16 & $68 \pm 13$ & $69 \pm 15$ & $67 \pm 12$ & 0.86 \\
\hline $\mathrm{HbA}_{1 \mathrm{c}}, \%$ & & $8.4 \pm 1.6$ & $8.5 \pm 1.9$ & $8.3 \pm 1.5$ & \\
\hline LDL cholesterol, $\mathrm{mmol} / \mathrm{l}$ & 46 & $2.9 \pm 0.9$ & $3.0 \pm 0.8$ & $2.8 \pm 0.9$ & 0.03 \\
\hline $\mathrm{LDL}>2.6 \mathrm{mmol} / 1, n(\%)$ & 46 & $433(59.8)$ & $69(70.4)$ & $364(58.2)$ & 0.02 \\
\hline HDL cholesterol, $\mathrm{mmol} / \mathrm{l}$ & 34 & $1.4 \pm 0.4$ & $1.3 \pm 0.3$ & $1.4 \pm 0.4$ & 0.03 \\
\hline $\mathrm{HDL}>1 \mathrm{mmol}, n(\%)$ & 34 & $587(79.8)$ & $79(79)$ & $508(79.9)$ & 0.84 \\
\hline Triglycerides, $\mathrm{mmol} / \mathrm{l}$ & 10 & $1.9 \pm 1.9$ & $2.2 \pm 1.8$ & $1.9 \pm 1.9$ & 0.07 \\
\hline Triglycerides $>1.7 \mathrm{mmol} / 1$ & 10 & $303(39.9)$ & $48(44.9)$ & $255(39.1)$ & 0.29 \\
\hline $\begin{array}{l}\text { Atherogenic dyslipidaemia, } \\
n(\%)\end{array}$ & 34 & $32(4.4)$ & $5(5.0)$ & $27(4.3)$ & 0.79 \\
\hline Creatinine clearance, $\mathrm{ml} / \mathrm{min}$ & 2 & $89.9 \pm 31.9$ & $87.4 \pm 32.8$ & $90.2 \pm 31.8$ & 0.34 \\
\hline Diabetic nephropathy, $n(\%)$ & 41 & $299(41.0)$ & $52(50.5)$ & $247(39.5)$ & 0.04 \\
\hline Peripheral artery disease, $n(\%)$ & 16 & $91(12.1)$ & $30(28.0)$ & $61(9.4)$ & $<0.0001$ \\
\hline Retinopathy, $n(\%)$ & 32 & $219(29.7)$ & $38(37.6)$ & $181(28.4)$ & 0.06 \\
\hline Biguanide, $n(\%)$ & 0 & $478(62.1)$ & $71(66.4)$ & $407(61.4)$ & 0.34 \\
\hline Sulphonylureas, $n(\%)$ & 0 & $345(44.8)$ & $53(49.5)$ & $292(44.0)$ & 0.30 \\
\hline$\alpha$-glucosidase inhibitors, $n(\%)$ & 0 & $81(10.5)$ & $14(13.1)$ & $67(10.1)$ & 0.39 \\
\hline Glitazone, $n(\%)$ & 0 & $96(12.5)$ & $6(5.6)$ & $90(13.6)$ & 0.02 \\
\hline Insulin, $n(\%)$ & 0 & $356(46.2)$ & $49(45.8)$ & $307(46.3)$ & 1 \\
\hline Antiplatelet drug, $n(\%)$ & 12 & $237(31.3)$ & $43(40.2)$ & $194(29.8)$ & 0.04 \\
\hline Statins, $n(\%)$ & 13 & $333(44.0)$ & $45(42.1)$ & $288(44.3)$ & 0.68 \\
\hline $\begin{array}{l}\text { Renin-angiotensin system } \\
\text { blockers, } n(\%)\end{array}$ & 13 & $447(59.0)$ & $67(62.6)$ & $380(58.5)$ & 0.46 \\
\hline
\end{tabular}

Values are mean $\pm \mathrm{SD}$ for quantitative variables or frequency for qualitative variables.

$P$ values indicate the significance of the difference between groups analysed using the Mann-Whitney test for quantitative variables and the Fisher's test for qualitative variables.

$57.4 \%$ of them were men and the mean time from diagnosis of diabetes was $13.4 \pm 9.3$ years. Regarding risk factors for cardiovascular disease, $12.0 \%$ had peripheral artery disease and $41.0 \%$ had diabetic nephropathy. The mean $\mathrm{HbA}_{1 \mathrm{c}}$ concentration was $68 \pm 13 \mathrm{mmol} / \mathrm{mol}(8.4 \pm 1.6 \%)$, mean LDL cholesterol was $2.8 \pm 0.8 \mathrm{mmol} / \mathrm{l}, 23.7 \%$ of participants were current smokers and $61.0 \%$ had hypertension. Regarding medication use, $54.0 \%$ were on lipid-lowering drugs ( $44.0 \%$ used statins), $31.3 \%$ were on antiplatelet drugs and $59.0 \%$ were on renin-angiotensin system blockers. Insulin-treated participants represented $46.3 \%$ of the cohort.

Of the 770 participants with diabetes, 107 (13.9\%) were found to be positive for silent myocardial ischaemia after screening. Men were four times more likely to be screened positive than women $(20.4 \%$ vs $5.2 \%$; $P<0.0001)$. Mean age and BMI did not differ significantly between patients with and without SMI (Table 1). Peripheral artery disease and nephropathy were significantly more prevalent in people with silent myocardial ischaemia than in people without $(28.0 \%$ vs $9.4 \%, P<0.0001$ and $50.5 \%$ vs $39.5 \%, P=0.04$, respectively). Those with silent myocardial ischaemia also had significantly higher systolic and diastolic blood pressure. Regarding biological variables, people with silent myocardial ischaemia had significantly lower HDL cholesterol and significantly higher LDL cholesterol levels; there was no difference in mean $\mathrm{HbA}_{1 \mathrm{c}}$ concentrations. Regarding medication use, people with silent myocardial ischaemia were more often treated with antiplatelet therapy $(40.2 \%$ vs $29.8 \% ; P=0.04)$, whereas use of statins, insulin and blockers of the renin-angiotensin system did not differ (Table 1).

\section{Patients' characteristics according to the screening period}

The characteristics and a comparison of the three groups, defined according to inclusion period, are shown in Table 2. The prevalence of silent myocardial ischaemia was $22.6 \%$ in 


\begin{tabular}{|c|c|c|c|c|}
\hline & $\begin{array}{l}\text { Screening period } 1 \\
(\mathrm{n}=257)\end{array}$ & $\begin{array}{l}\text { Screening period } 2 \\
(\mathrm{n}=241)\end{array}$ & $\begin{array}{l}\text { Screening period } 3 \\
\mathrm{n}=272 \text { ) }\end{array}$ & $P$ \\
\hline Silent myocardial ischaemia, $n(\%)$ & $58(22.6)$ & $33(13.7)$ & $16(5.9)$ & $<0.0001$ \\
\hline Men, $n(\%)$ & $147(57.2)$ & $147(61.0)$ & $148(54.4)$ & 0.32 \\
\hline Age, years & $62.3 \pm 9.3$ & $61.5 \pm 8.6$ & $62.9 \pm 9.7$ & 0.29 \\
\hline BMI, $\mathrm{kg} / \mathrm{m}^{2}$ & $29.2 \pm 5.4$ & $30.8 \pm 5.3$ & $31.0 \pm 6.3$ & 0.0005 \\
\hline Time from diagnosis of diabetes, years & $13.6 \pm 9.0$ & $12.5 \pm 9.1$ & $14.0 \pm 9.7$ & 0.14 \\
\hline Smoking, $n(\%)$ & $62(24.1)$ & $57(23.4)$ & $64(23.5)$ & 0.99 \\
\hline Systolic blood pressure, $\mathrm{mmHg}$ & $137.8 \pm 19.7$ & $129.9 \pm 16.3$ & $128.5 \pm 16.7$ & $<0.0001$ \\
\hline Diastolic blood pressure, $\mathrm{mmHg}$ & $76.3 \pm 11.2$ & $71.9 \pm 9.7$ & $70.2 \pm 10.3$ & $<0.0001$ \\
\hline Hypertension, $n(\%)$ & $198(77.3)$ & $137(56.9)$ & $132(48.5)$ & 0.45 \\
\hline $\mathrm{HbA}_{1 \mathrm{c}}, \mathrm{mmol} / \mathrm{mol}$ & $73 \pm 15$ & $67 \pm 12$ & $64 \pm 10$ & $<0.0001$ \\
\hline $\mathrm{HbA}_{1 \mathrm{c}}, \%$ & $8.8 \pm 1.8$ & $8.3 \pm 1.5$ & $8.0 \pm 1.3$ & \\
\hline LDL cholesterol, $\mathrm{mmol} / \mathrm{l}$ & $3.2 \pm 0.9$ & $2.8 \pm 0.9$ & $2.6 \pm 0.9$ & $<0.0001$ \\
\hline HDL cholesterol, $\mathrm{mmol} / \mathrm{l}$ & $1.3 \pm 0.4$ & $1.4 \pm 0.5$ & $1.4 \pm 0.4$ & 0.007 \\
\hline Triglycerides, mmol/l & $2.0 \pm 2.1$ & $1.9 \pm 1.8$ & $1.7 \pm 1.7$ & 0.41 \\
\hline Atherogenic dyslipidemia, $n(\%)$ & $11(4.4)$ & $13(5.7)$ & $8(3.1)$ & 0.38 \\
\hline Creatinine clearance, $\mathrm{ml} / \mathrm{min}$ & $90.0 \pm 30.7$ & $91.2 \pm 30.4$ & $88.5 \pm 34.4$ & 0.28 \\
\hline Diabetic nephropathy, $n(\%)$ & $103(42.9)$ & $95(40.8)$ & $101(39.5)$ & 0.73 \\
\hline Peripheral artery disease, $n(\%)$ & $28(11.0)$ & $33(13.8)$ & 30 (11.6) & 0.61 \\
\hline Retinopathy, $n(\%)$ & $98(39.0)$ & $62(27.3)$ & $59(22.7)$ & 0.0002 \\
\hline Biguanides, $n(\%)$ & $150(58.4)$ & $153(63.5)$ & $175(64.3)$ & 0.32 \\
\hline Sulfonylureas, $n(\%)$ & $125(48.6)$ & $111(46.1)$ & $109(40.0)$ & 0.13 \\
\hline$\alpha$-glucosidase inhibitors, $n(\%)$ & $46(17.9)$ & $19(7.9)$ & $16(5.9)$ & $<0.0001$ \\
\hline Glitazone, $n(\%)$ & $1(0.39)$ & $35(14.5)$ & $60(22.1)$ & $<0.0001$ \\
\hline Insulin, $n(\%)$ & $119(46.3)$ & $107(44.4)$ & $130(47.8)$ & 0.75 \\
\hline Antiplatelet drug & $72(28.2)$ & $70(29.1)$ & $95(36.3)$ & 0.10 \\
\hline Statins, $n(\%)$ & $88(34.7)$ & $92(38.2)$ & $153(58.4)$ & $<0.0001$ \\
\hline Renin-angiotensin system blockers, $n(\%)$ & $146(57.0)$ & $149(62.3)$ & $152(58.0)$ & 0.45 \\
\hline
\end{tabular}

*Period 1: July 1999 to December 2002; period 2: January 2003 to December 2005; period 3: January 2006 to December 2009. Values are mean \pm SD for quantitative variables or frequency for qualitative variables.

$P$ values indicate the significance of the differences among these three periods of time, analysed with the Kruskall-Wallis test for quantitative variables and the chi-squared test for qualitative variables.

period 1 (1999-2002) and had significantly declined to $13.7 \%$ in period $2(2003-2005)$ and to $5.9 \%$ in period 3 (2006-2009; $P<0.0001)$. The proportion of men, mean age, time from diagnosis of diabetes, prevalence of smoking and prevalence of peripheral artery disease did not differ significantly among the three groups. By contrast, a decrease over time was observed for mean systolic blood pressure and mean diastolic blood pressure; however, no associated increase in the use of renin-angiotensin system blockers was observed. Furthermore, mean $\mathrm{HbA}_{1 \mathrm{c}}$ significantly fell from $8.8 \%(73 \pm 15 \mathrm{mmol} / \mathrm{mol})$ in period 1 to $8.0 \%$ (64 \pm $10 \mathrm{mmol} / \mathrm{mol})$ in period $3(P<0.0001)$. Regarding medications for diabetes, only glitazone use significantly increased over time. No differences in biguanide or insulin use were observed. Mean LDL cholesterol levels significantly declined, while statin use increased. Lastly, antiplatelet drugs tended to be used more often in period 3 than in period 1 , although this difference did not reach significance.

\section{Prevalence of risk factors for silent myocardial ischaemia}

When considering all factors associated with silent myocardial ischaemia overall, male gender, presence of peripheral artery disease, high diastolic blood pressure and high LDL cholesterol were associated with an increased risk (Table 3, multivariate model 1). After further adjustment for the screening period, we found that male gender, peripheral arterial disease and the screening period (period 2 vs period 1 only) were significantly associated with silent myocardial ischaemia, but the effects of diastolic blood pressure and LDL cholesterol were no longer significant (Table 3, multivariate model 2 ). When comparing the first period and the second and third periods considered together, we observed a decrease in the proportion of participants with diastolic blood pressure $>80 \mathrm{mmHg}$ (from $52.5 \%$ to $23.6 \%$; $P<0.0001$ ) or LDL cholesterol $>2.6 \mathrm{mmol} / \mathrm{l}$ (from $77.4 \%$ to $51.1 \% ; P<0.0001)$.

\section{Discussion}

In this repeated cross-sectional study in asymptomatic people with Type 2 diabetes at high risk of coronary artery disease, we observed a highly significant decrease in the prevalence of silent myocardial ischaemia over the 10 -year study period. In parallel, control of the main cardiovascular disease risk factors improved over time, after an update in recommendations, with an increase in cardiovascular medications used. To our knowledge, only few studies have investigated silent 
Table 3 Predictive factors for silent myocardial ischaemia in the whole cohort

\begin{tabular}{lll}
\hline & $\begin{array}{l}\text { Multivariate } \\
\text { model 1 } \\
\text { Adjusted odds } \\
\text { ratio }(95 \% \mathrm{CI})\end{array}$ & $\begin{array}{l}\text { Multivariate } \\
\text { model 2 } \\
\text { Adjusted odds } \\
\text { ratio }(95 \% \mathrm{CI})\end{array}$ \\
\hline $\begin{array}{l}\text { Sex (men vs women) } \\
\text { Peripheral artery } \\
\text { disease }\end{array}$ & $\begin{array}{l}5.7(3.0-10.7) \\
4.2(2.3-7.4)\end{array}$ & $\begin{array}{l}5.8(3.1-10.8) \\
4.5(2.5-8.0)\end{array}$ \\
$\begin{array}{l}\text { Diastolic blood } \\
\text { pressure }>80 \mathrm{mmHg}\end{array}$ & $1.8(1.1-2.9)$ & - \\
$\begin{array}{l}\text { LDL cholesterol > 2.6 } \\
\text { mmol/l }\end{array}$ & $2.0(1.2-3.4)$ & - \\
$\begin{array}{l}\text { Screening period 2 vs } \\
1\end{array}$ & - & $0.38(0.22-0.68)$ \\
$\begin{array}{l}\text { Screening period 3 vs } \\
2\end{array}$ & - & $0.57(0.29-1.14)$ \\
\hline
\end{tabular}

Multivariate model 1: variables associated with silent myocardial ischaemia overall with $P<0.15$ were entered in the model in a stepwise manners: sex (men vs women), systolic blood pressure $(<130$ or $>130 \mathrm{mmHg})$, diastolic blood pressure $(<80$ or $>80$ $\mathrm{mmHg}$ ), hypertension, LDL ( $<2.6$ or $>2.6 \mathrm{mmol} / \mathrm{l})$, HDL cholesterol, triglycerides, creatinine clearance $(<80$ or $>80 \mathrm{ml} / \mathrm{min})$, diabetic nephropathy, peripheral artery disease, retinopathy. Multivariate model 2: the screening period $(1,2,3)$ was introduced into the model in addition to variables entered in model 1.

Screening periods: period 1, July 1999 to December 2002; period 2, January 2003 to December 2005; period 3, January 2006 to December 2009.

myocardial ischaemia prevalence and cardiovascular disease risk factor management concomitantly, although screening for silent myocardial ischaemia is frequently discussed.

Data on silent myocardial ischaemia prevalence are not consistent in the literature, with values in people with diabetes varying from $12 \%$ to $62 \%$. This discrepancy was notably explained in part by differences in patient selection and choice of stress test [13]. For example, in the large Milan Study on Atherosclerosis and Diabetes (MiSAD), enrolling 925 asymptomatic participants with Type 2 diabetes, the prevalence of silent myocardial ischaemia assessed by a stress ECG treadmill test was as low as $12 \%$, but the screened population was at very low risk, with no requirement for additional risk factors for enrolment [14]. In a similar population, Cosson et al. [15] reported a 33\% prevalence of silent myocardial ischaemia using single-photon emission computed tomography. Ten years ago, we reported a $31 \%$ prevalence using stress ECG, coupled with myocardial perfusion imaging, in high-risk Type 2 diabetes [16]. Recent studies, however, report a lower prevalence $[3,17]$.

Regarding the threshold for cardiovascular risk factor control, management of cardiovascular disease risk factors in the present cohort improved over time but cannot be considered as optimal, as also reported by two recent large studies $[18,19]$. Indeed, in the present study population, the lowest prevalence of silent myocardial ischaemia was associated with an average $\mathrm{HbA}_{1 \mathrm{c}}$ of $8 \%(64 \mathrm{mmol} / \mathrm{mol})$, which does not reflect tight glycaemic control; however, this finding should be considered together with the results of the ACCORD, VADT and ADVANCE studies [20-22]. These three major studies in people with high risk Type 2 diabetes showed no significant benefit of tight glycaemic control in terms of reduction in macrovascular complications in people with diabetes with high cardiovascular risk. Nevertheless, the 10-year follow-up UK Prospective Diabetes Study showed that intensive glucose control was associated with a significantly decreased risk of myocardial infarction and death from any cause in the longer term [23]. Furthermore, the results from the ACCORD study suggest that very tight control $\left(\mathrm{HbA}_{1 \mathrm{c}}<6.0 \%\right)$ might actually be detrimental to those with pre-existing cardiovascular disease and long duration of diabetes [21].

The mean LDL concentration in the present population at the end of the study had decreased from 3.1 to $2.6 \mathrm{mmol} / \mathrm{l}$, which was probably attributable to an increase in statin use; however, once again, this does not reflect tight control with regard to this cardiovascular risk factor. As stated in current guidelines, decreasing LDL concentration to an even greater extent should be beneficial in term of cardiovascular risk, with an LDL cholesterol target of $<1.8 \mathrm{mmol} / \mathrm{l}$ [24]. Tight control of lipid levels may therefore be associated with a greater reduction in silent myocardial ischaemia prevalence. By contrast, optimum blood pressure control appears to have been achieved, given the values observed in the present study. No argument is put forward in the literature in defence of a lower target [25], and too great a decrease in blood pressure may even be detrimental [26].

In the present study, high LDL cholesterol and high diastolic blood pressure were risk factors for silent myocardial ischaemia; however, such associations were no longer significant after adjustment for the period of inclusion. We can therefore hypothesize that the decrease in silent myocardial ischaemia prevalence observed throughout the study can be explained by an improvement in management of cardiovascular risk factors, such as diastolic blood pressure or LDL cholesterol level, even though definitive conclusions cannot be drawn from the present study. Nevertheless, the results are in accordance with Barthelemy et al. [27], who reported a much lower prevalence of silent myocardial ischaemia $(16 \%)$ in people receiving intensive cardiovascular risk factor therapy than that reported previously in people receiving conventional care for cardiovascular risk factors [27]. Indeed, the 122 participants in their observational study benefited from long-term intensive therapy with better control of cardiovascular risk factors (blood pressure: 133/ 73 vs $139 / 76 \mathrm{mmHg}$; LDL cholesterol: 2.6 vs $3.1 \mathrm{mmol} / \mathrm{l}$; and glycaemia: $\mathrm{HbA}_{1 \mathrm{c}} 60.7 \mathrm{mmol} / \mathrm{mmol}$ vs $79.2 \mathrm{mmol} /$ mmol). Although the study was small, to our knowledge, no other publication has reported such an association. In the DIAD study, all screened participants who had not experienced cardiac events or revascularization were also invited to return for stress myocardial perfusion imaging 3 years after 
entry; repeat tests performed in 358 participants overall showed significant improvement in myocardial perfusion imaging defects [6]. The significant increase in primary medical prevention observed across the study was thought to explain such improvements. In the BARI 2D trial, which included people with Type 2 diabetes and angiographically documented stable coronary heart disease, the number of risk factors controlled during the trial was strongly related to death and cardiovascular events [28]. Moreover, the decrease in silent myocardial ischaemia prevalence may also be attributable to the marked increase in glitazone use over the study period, although this causality link cannot be established from the present results. Indeed, glitazone use has been associated with decreased risks of heart failure, cardiovascular disease and all-cause mortality [29]. However, glitazones were withdrawn in France in 2011.

The present study has some limitations, in particular, the risk of bias inherent to its observational design. The enrolment of all eligible participants during the study period may have limited selection bias, as supported by the very similar number of participants enrolled during each interval. However, we cannot exclude the possibility that an increasing number of people were screened prior to entry into this study because of increased awareness of the presence of silent myocardial ischaemia among primary care physicians which may have contributed to the decreased prevalence observed in our study. Moreover, during the course of the study, Type 2 diabetes may have been diagnosed at earlier stages of the disease; physicians were more aware of the condition and may have screened for it earlier. In addition, the present study was conducted in only one hospital; however, most of the complicated patients in the region are likely to be referred to our centre, limiting selection bias. Moreover, we cannot exclude the possibility that routine clinical management of patients could have evolved through time, as the inclusion period is rather long. Nevertheless, the single-photon emission computed tomography method used may have been increasingly sensitive because of increasing experience among specialists, reinforcing our observation. Better specificity of screening technique, however, may have induced a decrease in the false-positive rate for silent myocardial ischaemia and therefore may have contributed to the observed decrease in the prevalence of the disease. Lastly, the observational study design does not allow conclusions to be drawn regarding causality link between decreasing prevalence of silent myocardial ischaemia and optimized cardiovascular risk factors or drug use.

In conclusion, positive screening for silent myocardial ischaemia affects a lower proportion of people with diabetes than it did a few years ago. Given the dynamic nature of myocardial ischaemia, the prohibitive cost of screening all asymptomatic patients, and the proven efficacy of primary preventive strategies, we recommend implementation of better clinical risk stratification strategies to identify very high-risk individuals. Indeed, European guidelines recommend the screening of only those at particularly high risk, such as people with evidence of peripheral artery disease, a high coronary artery calcium score or proteinuria [9]. Several questions remain unclear: (1) what is the best strategy to allow proper patient selection through logical stepwise approaches to screening? and (2) would rigorously implemented primary preventive measures alter patient outcomes?

The results of the present study are consistent with current recommendations that advocate glycaemic control and intensive management of cardiovascular risk factors instead of systematic screening for silent myocardial ischaemia.

\section{Funding sources}

None.

\section{Competing interests}

None declared.

\section{References}

1 International Diabetes Federation: Diabetes Atlas update poster, 6th edition. Brussels, Belgium, 2014.

2 Sarwar N, Gao P, Seshasai SR, Gobin R, Kaptoge S, Di Angelantonio $\mathrm{E}$ et al. Diabetes mellitus, fasting blood glucose concentration, and risk of vascular disease: a collaborative meta-analysis of 102 prospective studies. Lancet 2010; 375: 2215-2222.

3 Davis TM, Coleman RL, Holman RR. Prognostic significance of silent myocardial infarction in newly diagnosed type 2 diabetes mellitus: United Kingdom Prospective Diabetes Study (UKPDS) 79. Circulation 2013; 127: 980-987.

4 Standards of medical care in diabetes-2014. Diabetes Care 2014; 37 (Suppl. 1): S14-80.

5 Expert Panel of Detection Evaluation and Treatment of High Blood Cholesterol in Adults. Executive Summary of The Third Report of The National Cholesterol Education Program (NCEP) Expert Panel on Detection, Evaluation, And Treatment of High Blood Cholesterol In Adults (Adult Treatment Panel III). JAMA 2001; 285: 2486-2497.

6 Young LH, Wackers FJ, Chyun DA, Davey JA, Barrett EJ, Taillefer $\mathrm{R}$ et al. Cardiac outcomes after screening for asymptomatic coronary artery disease in patients with type 2 diabetes: the DIAD study: a randomized controlled trial. JAMA 2009; 301: 1547-1555.

7 Muhlestein JB, Lappe DL, Lima JA, Rosen BD, May HT, Knight S et al. Effect of screening for coronary artery disease using CT angiography on mortality and cardiac events in high-risk patients with diabetes: the FACTOR-64 randomized clinical trial. JAMA 2014; 312: 2234-2243.

8 Lievre MM, Moulin P, Thivolet C, Rodier M, Rigalleau V, Penfornis A et al. Detection of silent myocardial ischemia in asymptomatic patients with diabetes: results of a randomized trial and meta-analysis assessing the effectiveness of systematic screening. Trials 2011; 12: 23.

9 Ryden L, Grant PJ, Anker SD, Berne C, Cosentino F, Danchin N et al. ESC Guidelines on diabetes, pre-diabetes, and cardiovascular diseases developed in collaboration with the EASD: the Task Force on diabetes, pre-diabetes, and cardiovascular diseases of the European Society of Cardiology (ESC) and developed in collaboration with the European Association for the Study of Diabetes (EASD). Eur Heart J 2013; 34: 3035-3087. 
10 Passa P, Drouin P, Issa-Sayegh M, Blasco A, Masquet C, Monassier JP et al. Coronary disease and diabetes]. Diabet Metab 1995; 21: 446-451.

11 Avignon A, Sultan A, Piot C, Mariano-Goulart D, Thuan Dit Dieudonne JF, Cristol JP et al. Osteoprotegerin: a novel independent marker for silent myocardial ischemia in asymptomatic diabetic patients. Diabetes Care 2007; 30: 2934-2939.

12 Valensi P, Avignon A, Sultan A, Chanu B, Nguyen MT, Cosson E. Atherogenic dyslipidemia and risk of silent coronary artery disease in asymptomatic patients with type 2 diabetes: a cross-sectional study. Cardiovasc Diabetol 2016; 15: 104.

13 Rutter MK, Nesto RW. The changing costs and benefits of screening for asymptomatic coronary heart disease in patients with diabetes. Nat Clin Pract Endocrinol Metab 2007; 3: 26-35.

14 Faglia E, Favales F, Calia P, Paleari F, Segalini G, Gamba PL et al. Cardiac events in 735 type 2 diabetic patients who underwent screening for unknown asymptomatic coronary heart disease: 5year follow-up report from the Milan Study on Atherosclerosis and Diabetes (MiSAD). Diabetes Care 2002; 25: 2032-2036.

15 Cosson E, Guimfack M, Paries J, Paycha F, Attali JR, Valensi P. Prognosis for coronary stenoses in patients with diabetes and silent myocardial ischemia. Diabetes Care 2003; 26: 1313-1314.

16 Avignon A, Sultan A, Piot C, Elaerts S, Cristol JP, Dupuy AM. Osteoprotegerin is associated with silent coronary artery disease in high-risk but asymptomatic type 2 diabetic patients. Diabetes Care 2005; 28: 2176-2180.

17 MacDonald MR, Petrie MC, Home PD, Komajda M, Jones NP, Beck-Nielsen $\mathrm{H}$ et al. Incidence and prevalence of unrecognized myocardial infarction in people with diabetes: a substudy of the Rosiglitazone Evaluated for Cardiac Outcomes and Regulation of Glycemia in Diabetes (RECORD) study. Diabetes Care 2011; 34: 1394-1396.

18 Gyberg V, De Bacquer D, De Backer G, Jennings C, Kotseva K, Mellbin L et al. Patients with coronary artery disease and diabetes need improved management: a report from the EUROASPIRE IV survey: a registry from the EuroObservational Research Programme of the European Society of Cardiology. Cardiovasc Diabetol 2015; 14: 133.

19 Farkouh ME, Boden WE, Bittner V, Muratov V, Hartigan P, Ogdie $\mathrm{M}$ et al. Risk factor control for coronary artery disease secondary prevention in large randomized trials. J Am Coll Cardiol 2013; 61: 1607-1615.
20 Duckworth W, Abraira C, Moritz T, Reda D, Emanuele N, Reaven $\mathrm{PD}$ et al. Glucose control and vascular complications in veterans with type 2 diabetes. N Engl J Med 2009; 360: 129-139.

21 Gerstein HC, Miller ME, Byington RP, Goff DC, Jr., Bigger JT, Buse JB et al. Effects of intensive glucose lowering in type 2 diabetes. N Engl J Med 2008; 358: 2545-2559.

22 Patel A, MacMahon S, Chalmers J, Neal B, Billot L, Woodward $\mathrm{M}$ et al. Intensive blood glucose control and vascular outcomes in patients with type 2 diabetes. N Engl J Med 2008; 358: 2560 2572.

23 Holman RR, Paul SK, Bethel MA, Matthews DR, Neil HA. 10-year follow-up of intensive glucose control in type 2 diabetes. $N$ Engl J Med 2008; 359: 1577-1589.

24 Catapano AL, Graham I, De Backer G, Wiklund O, Chapman MJ, Drexel $\mathrm{H}$ et al. 2016 ESC/EAS Guidelines for the Management of Dyslipidaemias: The Task Force for the Management of Dyslipidaemias of the European Society of Cardiology (ESC) and European Atherosclerosis Society (EAS) Developed with the special contribution of the European Assocciation for Cardiovascular Prevention \& Rehabilitation (EACPR). Atherosclerosis 2016; 253 : 281-344.

25 Mancia G, Fagard R, Narkiewicz K, Redon J, Zanchetti A, Bohm $\mathrm{M}$ et al. $2013 \mathrm{ESH} / \mathrm{ESC}$ guidelines for the management of arterial hypertension: the Task Force for the Management of Arterial Hypertension of the European Society of Hypertension (ESH) and of the European Society of Cardiology (ESC). Eur Heart J 2013; 34 : 2159-2219.

26 Nilsson PM: Blood pressure control in type 2 diabetes over time what can we learn from different trajectories? J Hypertens 2015; 33: 2018-2019.

27 Barthelemy O, Jacqueminet S, Rouzet F, Isnard R, Bouzamondo A, Le Guludec D et al. Intensive cardiovascular risk factors therapy and prevalence of silent myocardial ischaemia in patients with type 2 diabetes. Arch Cardiovasc Dis 2008; 101: 539-546.

28 Bittner V, Bertolet M, Barraza Felix R, Farkouh ME, Goldberg S, Ramanathan KB et al. Comprehensive Cardiovascular Risk Factor Control Improves Survival: The BARI 2D Trial. J Am Coll Cardiol 2015; 66: 765-773.

29 Hippisley-Cox J, Coupland C. Diabetes treatments and risk of heart failure, cardiovascular disease, and all cause mortality: cohort study in primary care. BMJ 2016; 354: 13477. 